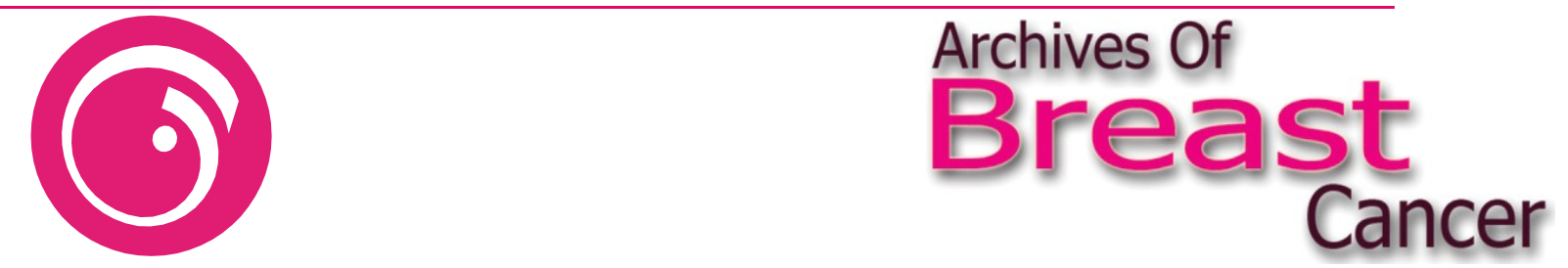

DOI: $10.32768 / a b c .202184318-328$

\title{
Management of Early Breast Cancer at an Australian Cancer Centre During the Early Phase of COVID-19 Pandemic
}

\author{
Elissa J Zhang ${ }^{\star a, b}$, Kirsty Stuartt ${ }^{\mathrm{a}, \mathrm{c}, \mathrm{e}}$, Rina Huil ${ }^{\mathrm{a}, \mathrm{c}, \mathrm{e}}$, Rhiannon Mellor $^{\mathrm{e}}$, Wei Wang ${ }^{\mathrm{a}, \mathrm{e}}$, Verity Ahern ${ }^{\mathrm{a}, \mathrm{c}, \mathrm{e}}$, Farid \\ ${\text { Meybodia,c }{ }^{\mathrm{a}} \text { James French }}^{\mathrm{a}, \mathrm{c}}$, Elisabeth Elder ${ }^{\mathrm{a}, \mathrm{c}}$, Meagan E Brennan ${ }^{\mathrm{a}, \mathrm{c}, \mathrm{d}}$ \\ aWestmead Breast Cancer Institute, Westmead Hospital, Westmead, NSW, Australia \\ ${ }^{b}$ Faculty of Medicine, University of New South Wales, Kensington, NSW, Australia \\ ${ }^{c}$ Westmead Clinical School, Faculty of Medicine and Health, University of Sydney, Westmead NSW, Australia \\ ${ }^{d}$ School of Medicine Sydney, University of Notre Dame Australia, Darlinghurst, NSW, Australia \\ ${ }^{e}$ Crown Princess Mary Cancer Centre, Westmead Hospital, Westmead, NSW, Australia
}

\section{ARTICLE INFO}

\section{Received:}

25 May 2021

Revised:

20 June 2021

Accepted:

24 June 2021

\section{ABSTRACT}

Background: This study aimed to prospectively record changes to treatment for early breast cancer patients during the first wave of the COVID-19 pandemic in Australia. The purpose was to assess the impact on breast cancer outcomes and to determine the need for any mitigative actions.

Methods: The study was conducted in the breast cancer unit of a tertiary referral hospital. Patients with early (non-metastatic) breast malignancy discussed in multidisciplinary team meetings between March and June 2020 were included. Patients were newly diagnosed, post-operative or post-neoadjuvant chemotherapy. Standard treatment was defined by Westmead Breast Cancer Institute protocols and any variations related to the pandemic were recorded.

Results: In the study, 145 patients were included (median age 59 years). Pandemic-related changes to management were noted in 13 of 145 (9.0\%) patients. Four patients experienced a delay to cancer treatments, four were not offered reconstructive/ symmetrisation surgical procedures, three had altered radiotherapy protocols and two patients were not offered enrolment to a clinical trial. These impacts affected the groups presenting with new cancers $(n=7 / 86,8.1 \%)$, postoperative cases $(n=4 / 25,16.0 \%)$ and post-neoadjuvant chemotherapy cases presenting for surgical planning $(n=2 / 34,5.9 \%)$.

Conclusion: Most patients (91.0\%) received standard treatment during the first Breast cancer, Coronavirus, surgery, radiotherapy, chemotherapy wave of the pandemic. The minor variations from institutional protocols observed in this study are unlikely to affect local control or survival in this patient cohort, but close follow-up is required. Quality of life may have been affected for four patients who had downgraded or delayed reconstructive procedures.

Copyright $($ 2021. This is an open-access article distributed under the terms of the Creative Commons Attribution-Non-Commercial 4.0 International License which permits copy and redistribution of the material in any medium or format or adapt, remix, transform, and build upon the material for any purpose, except for commercial purposes.

\footnotetext{
* Address for correspondence:

Elissa Zhang, MD

Address: Westmead Breast Cancer Institute, Westmead Hospital, Block F/189 Cnr, Hawkesbury \& Darcy Rd, Westmead NSW 2145, Australia

Tel : +61 288906728

Email: elissa.zhang@health.nsw.gov.au
}

\section{INTRODUCTION}

During the early phase of the COVID-19 pandemic in Australia (March to June 2020), restrictions were placed on the treatment of early breast cancer following public health recommendations to contain the spread of the novel coronavirus. ${ }^{1}$ In the state of New South Wales 
(NSW), the national population screening program BreastScreen closed between late March and early May, and elective surgery was suspended between 25 March and 1 July of 2020. ${ }^{2}$ Professional bodies in Australia and world-wide released guidelines for cancer treatment due to the pandemic (Table 1). ${ }^{3-6}$ The type and extent of breast cancer operations were minimized to reduce hospital admission days and risk of complications. Surgery for low grade DCIS, re-excision of involved margins, complex oncoplastic procedures, contralateral risk-reducing or symmetrising procedures and most breast reconstruction were recommended against. ${ }^{1,4}$ Radiotherapy and chemotherapy restrictions mandated considering the risks and benefits of treatment to minimize the numbers of patients attending hospital and numbers of immunosuppressed patients in the community. This included staged plans to reduce radiotherapy if staff illness reduced capacity, using hypofractionation, omitting boost treatments, and omitting treatment for DCIS and invasive cancer in older women. ${ }^{7}$ Systemic treatment recommendations included the use of G-CSF with chemotherapy, neoadjuvant or adjuvant endocrine therapy without chemotherapy for patients with low risk ERpositive/HER2-negative breast cancer, trastuzumab and paclitaxel without anthracycline-based chemotherapy for node negative small size HER2-positive cancer, delay of routine follow-up echocardiograms, and bone mineral density scans. ${ }^{8-10}$ Many consultations during treatment and follow-up were moved to telehealth.

Table 1. COVID-19 recommendations and restrictions in NSW.

\begin{tabular}{ll}
\hline Recommending body & Recommendation \\
\hline & Elective surgery during COVID-19 \\
& Surgery restricted to Category 1 (most urgent) only. No non-urgent surgery. \\
NSW Health- Government & Implemented 25/3/2020; staged return to normal from 17/4/2020. (Relevance for breast \\
(Health Directive) & service: No breast reconstruction, risk reducing surgery, complex oncoplastic procedures or \\
& contralateral procedures during this time.)
\end{tabular}

Guidelines from BreastSurgANZ Council relating to the COVID-19 pandemic

Breast Surgeons of Australia and New Zealand (Guidelines) $^{4}$

Australian Society of
Plastic Surgeons and Breast
Surgeons of Australia and
New Zealand
(Position statement) $^{3}$

Royal Australian and New Zealand College of Radiologists (Guidance) ${ }^{7}$

Peter MacCallum Cancer Centre, Victoria, Australia (Department of Radiation Oncology, Clinical Response Plan $)^{5}$
Surgery should be restricted to Category 1 cases. Defer surgery for low and intermediate grade DCIS. Limit complexity of surgery- consider deferral of immediate breast reconstruction and contralateral risk reducing mastectomy. Reconsider need and delivery of chemotherapy. Consider neoadjuvant endocrine therapy when surgery is delayed. Rigorous MDT* discussion and documentation are required.

\section{Position statement regarding breast reconstruction during the COVID-19 pandemic}

In general, breast reconstruction should be delayed. Delayed breast reconstruction and planned secondary or revision breast reconstruction should be postponed. Immediate autologous flap reconstruction for breast reconstruction should be delayed where possible. Immediate tissue expander or direct to implant reconstruction can be evaluated on a case-bycase basis.

\section{Principles for Radiation Oncology Practices}

In summary, limiting transmission where possible, segregation of teams, segregation of well patients from those with or with suspected COVID-19, maximizing communication between staff members, and for radiotherapy protocols consideration of shorter fractionation, delay in commencement of treatment, very low risk disease deferment.

\section{COVID-19 Clinical Response Plan for Radiation Oncology}

Advising patients should stay away if unwell with COVID-19 symptoms, staff quarantine after exposure, reduction of transmission on hard surfaces, hand sanitization, reduction in visitor access, increased telehealth facilities, segregation of teams, working from home where possible, avoidance of non-essential contact.

The plan also discusses service impact levels correlating with proportion of working staff available. 


\begin{tabular}{ll}
\hline Recommending body & Recommendation \\
\hline & $\begin{array}{l}\text { Practical Considerations for Treating Patients With Cancer in the COVID-19 Pandemic } \\
\text { In summary, strongly consider the use of primary prophylactic G-CSF with second- and third- } \\
\text { generation adjuvant regimens, identify patients for no requirement of chemotherapy or less } \\
\text { Medical Oncology Group } \\
\text { of Australia }\end{array}$ \\
$\begin{array}{l}\text { intensive regimens where possible, e.g., neoadjuvant and adjuvant endocrine therapy without } \\
\text { chemotherapy for low-risk ER positive/HER2 negative cancer, paclitaxel with trastuzumab } \\
\text { without AC for small size, node negative, HER2 positive cancer and conversion to telehealth } \\
\text { consultations where possible. }\end{array}$ \\
\hline
\end{tabular}

From May 2020, there was a staged easing of restrictions in public hospitals in NSW after a sixweek period of 'lockdown'. Social distancing rules, mask wearing and limitations on hospital visitors remained until March 2021. Overall NSW experienced a low COVID-19 caseload, peaking at 213 cases in a single day in late March 2020 (Figure 1 ), with a cumulative total of 56 deaths. ${ }^{11,12}$

Nationally subsidised breast cancer related imaging including mammogram, 3D-tomosynthesis and MRI decreased by $37 \%$ from March to April 2020, before fully returning to pre-COVID service numbers in June 2020. ${ }^{13}$ Mastectomies, breast lesion excisions and axillary lymph node procedures in public hospitals across Australia remained stable in March to April before decreasing by 33\% in May, reflecting the flow-on effects of reductions in imaging and subsequent cancer diagnoses. ${ }^{13}$

Impacts on early breast cancer treatments during this period may have resulted in sub-optimal treatment, placing them at risk of recurrence or other complications. For example, if a patient did not have an involved margin re-excised, or had altered radiotherapy and chemotherapy regimes, there might be a higher risk of local or distant relapse. Quality of life might be adversely affected if oncoplastic procedures or breast reconstructions were not offered. Understanding alterations to management will help to plan future care and surveillance for patients treated during this time.

The aim of this study was to prospectively document and analyse any changes to treatment for early (non-metastatic) breast cancer during the first wave of the COVID-19 pandemic in NSW, compared to evidence-based protocols.

\section{METHODS}

This study was conducted at the breast cancer unit of a tertiary referral hospital (the NSW Westmead Hospital Breast Cancer Institute) between March 15 to June 15, 2020 during the most severe restrictions on hospital treatment. Inclusion criteria were: female patients who were either newly diagnosed DCIS or non-metastatic invasive cancer, post-operative, or finishing neo-adjuvant chemotherapy (NACT), who were being discussed in MDT meetings held three times a week during the study period. Patients with benign lesions or recurrent/metastatic breast cancer were excluded. Patient demographic and cancer data were collected. Each case was allocated a category of "new cancer", "post-op cancer" and "post-NACT", corresponding to the reason for their first MDT discussion during the study period. Therefore, new cancer cases referred before the study period were classified as 'post-operative' or 'post-neoadjuvant' when re-discussed at MDT meeting. Management recommended by the MDT was recorded and any changes from local protocols ('ideal' management) caused by COVID-19 restrictions were documented.

Data were collected in an Excel spreadsheet and analysed in IBM SPSS v26. Cases where the actual (MDT-recommended) management differed from the 'ideal' management were identified, examined in detail and were flagged for recall for closer follow-up post COVID-19 restrictions easing.

\section{Ethical Approval}

The study was registered with the Australian New Zealand Clinical Trials Registry (ACTRN12620000869976). Approval was obtained from the Western Sydney Local Health District Human Research Ethics Committee (Project ID 2020/PID00900).

\section{RESULTS}

There were 344 new referrals to the institute (86 new malignancies; the remainder atypical or benign). This compares to 456 cases (109 new malignancies) for the same three-month period in 2019, a $24.6 \%$ reduction in total new referrals and a $21.1 \%$ reduction in new malignancy referrals.

Overall, 145 eligible cases of early breast cancer (DCIS or invasive cancer) were discussed across the MDT meetings. The demographics of the study population are shown in Table 2. All patients were female. Median age was 59 years.

All patients had core biopsies of the breast performed prior to referral or organised through the institute. The majority of patients $(\mathrm{n}=123,84.8 \%)$ had invasive cancer, and 22 (15.2\%) had DCIS on biopsy results. 
Table 2. Participant and cancer demographics.

\begin{tabular}{|c|c|c|c|}
\hline Variables & & & N (\%) \\
\hline Age (years) & Mean & 57.7 (SD 11.8) & - \\
\hline \multirow[t]{6}{*}{ Age groups (years) } & $30-39$ & & $11(7.6)$ \\
\hline & $40-49$ & & 23 (15.9) \\
\hline & $50-59$ & & $46(31.7)$ \\
\hline & $60-69$ & & $40(27.6)$ \\
\hline & $70-79$ & & $20(13.8)$ \\
\hline & $80+$ & & $5(3.4)$ \\
\hline Cancer Demographics & & $\begin{array}{c}\text { Core Biopsy } \\
\begin{array}{c}(\mathrm{n}=145) \\
\mathrm{N}(\%)\end{array}\end{array}$ & $\begin{array}{c}\text { Surgical Histology } \\
(\mathrm{n}=127) \\
\text { N (\%) }\end{array}$ \\
\hline DCIS & & $22(15.2)$ & 15 (11.8) \\
\hline \multirow[t]{4}{*}{ Grade } & Low & $2(9.1)$ & 0 \\
\hline & Intermediate & $11(50.0)$ & $10(66.7)$ \\
\hline & High & $7(31.8)$ & $5(33.3)$ \\
\hline & Missing & $2(9.1)$ & \\
\hline Invasive cancer & & $123(84.8)$ & $109(86.5)$ \\
\hline \multirow[t]{6}{*}{ Histological Type } & No specific type & 88 (71.5) & $77(70.6)$ \\
\hline & Infiltrating lobular carcinoma & $18(14.6)$ & $18(16.5)$ \\
\hline & Invasive other & $13(10.6)$ & $8(7.3)$ \\
\hline & Atypical ** & $3(2.4)$ & - \\
\hline & pCR & NA & $6(5.5)$ \\
\hline & Missing & $1(0.8)$ & - \\
\hline \multirow[t]{4}{*}{ Histological Grade } & 1 & $17(13.8)$ & $23(21.1)$ \\
\hline & 2 & $65(52.8)$ & 53 (48.6) \\
\hline & 3 & $25(20.3)$ & $24(22.0)$ \\
\hline & Missing & $16(13.0)$ & $9(8.3)$ \\
\hline \multirow[t]{3}{*}{ Receptor status } & ER positive & 97 (78.9) & $90(82.6)$ \\
\hline & HER2 positive & $18(14.6)$ & $11(10.1)$ \\
\hline & Triple negative & $13(10.6)$ & $7(6.4)$ \\
\hline
\end{tabular}

*Including invasive tubular, invasive mucinous, invasive papillary, invasive carcinoma

** Atypical including atypical apocrine, atypical hyperplasia

NA=not applicable

Details of presentation (reason for discussion by the MDT) are shown in Table 3. Of the sample, 86 (59.3\%) were new cancer cases, 25 (17.2\%) were post-operative cancer cases and 34 (23.4\%) were cases returning for surgical planning after neoadjuvant chemotherapy. Of the 86 new cancer referrals, up-front surgery was recommended in 69 (80.2\%) cases and neoadjuvant therapies in 17 (19.8\%) cases.

\section{COVID-related changes to treatment}

Changes to management related to COVID-19 were recorded in 13 of 145 (9.0\%) patients. Of these, four patients experienced a delay to cancer treatments, four were not offered their ideal reconstructive or symmetrisation procedures, three had altered radiotherapy protocols and two were not recruited to eligible clinical trials. These impacts mostly affected new cancer patients $(n=7,54 \%)$, followed by postoperative $(n=4,31 \%)$, then post-NACT $(n=2,15 \%)$. (Table 4).

\section{Changes to surgery}

Six patients experienced COVID-related changes to surgical management:

- Two patients with intermediate grade DCIS less than $20 \mathrm{~mm}$ in size had their surgery deferred. 
They showed no microinvasion on surgical histopathology and were both treated with breast conservation surgery when restrictions were lifted. Patient $\mathrm{C}$ had surgery delayed by three months, and Patient $\mathrm{E}$ by only ten days.

- Patients B, F and L were denied immediate contralateral symmetrising breast reduction, breast reconstruction for low grade DCIS, and contralateral prophylactic mastectomy, respectively. Delayed surgical procedures were planned. One patient requested autologous reconstruction, which was changed to implantbased reconstruction.

Table 3. Reason for discussion at MDT and treatment recommendations during COVID-19 period of restriction (N=145)

\begin{tabular}{|c|c|c|}
\hline \multirow{2}{*}{$\begin{array}{l}\text { Reason and Recommendations } \\
\text { Group 1: New cancer }\end{array}$} & \multicolumn{2}{|l|}{$\mathbf{N}(\%)$} \\
\hline & \multicolumn{2}{|c|}{$86(59.3)$} \\
\hline $\begin{array}{l}\text { Upfront surgery } \\
\text { Breast }\end{array}$ & \multicolumn{2}{|l|}{$69(80.2)$} \\
\hline Wide local excision (WLE) +/- local flap & \multicolumn{2}{|l|}{$53(76.8)$} \\
\hline WLE + contralateral summarization & \multicolumn{2}{|l|}{$1(1.4)$} \\
\hline Simple mastectomy & \multicolumn{2}{|l|}{$9(13.0)$} \\
\hline Mastectomy and immediate reconstruction & \multicolumn{2}{|l|}{$4(5.8)$} \\
\hline Excision of atypical lesions & \multicolumn{2}{|l|}{$2(2.9)$} \\
\hline \multicolumn{3}{|l|}{ Axilla } \\
\hline Sentinel lymph node biopsy alone & \multicolumn{2}{|l|}{$54(78.3)$} \\
\hline Axillary lymph node dissection & \multicolumn{2}{|l|}{$3(4.3)$} \\
\hline No axillary surgery (DCIS) & \multicolumn{2}{|l|}{$12(17.4)$} \\
\hline Neoadjuvant therapy & \multicolumn{2}{|l|}{$17(19.8)$} \\
\hline Chemo/targeted & \multicolumn{2}{|l|}{$13(76.5)$} \\
\hline Endocrine only & \multicolumn{2}{|l|}{$4(23.5)$} \\
\hline COVID-related changes & $7(8.1)$ & See Table 4; Cases A-G \\
\hline Group 2: Post-operative Cancer & \multicolumn{2}{|l|}{$25(17.2)$} \\
\hline Further breast surgery & \multicolumn{2}{|l|}{$6(24.0)$} \\
\hline Further axillary surgery & \multicolumn{2}{|l|}{$3(12.0)$} \\
\hline COVID-related change & $4(16.0)$ & See Table 4; Cases H-K \\
\hline Group 3: Post NACT surgical planning & \multicolumn{2}{|l|}{$34(23.4)$} \\
\hline \multicolumn{3}{|l|}{ Breast } \\
\hline WLE & \multicolumn{2}{|l|}{$22(64.7)$} \\
\hline Simple mastectomy & \multicolumn{2}{|l|}{$7(20.6)$} \\
\hline Mastectomy and immediate reconstruction & \multicolumn{2}{|l|}{$5(14.7)$} \\
\hline \multicolumn{3}{|l|}{ Axilla } \\
\hline Sentinel lymph node biopsy alone & \multicolumn{2}{|l|}{$14(41.2)$} \\
\hline Axillary lymph node dissection & \multicolumn{2}{|l|}{$12(35.3)$} \\
\hline Targeted axillary dissection & \multicolumn{2}{|l|}{8 (23.5) } \\
\hline COVID-related change & $2(5.9)$ & See Table 4; Cases L-M \\
\hline
\end{tabular}


Table 4. COVID-19 related changes to treatment

\begin{tabular}{|c|c|c|c|c|c|}
\hline Case & Age & Category & $\begin{array}{c}\text { Cancer } \\
\text { information }\end{array}$ & $\begin{array}{l}\text { Treatment } \\
\text { Changed }\end{array}$ & Details \\
\hline A & 71 & New cancer & $\begin{array}{l}\text { pT1cN0M0 } \\
\text { Inv NST G1 } \\
\text { ER+PR+HER2- }\end{array}$ & Trial & $\begin{array}{l}\text { Not recruited for clinical trial } \\
\text { due to trial recruitment shut } \\
\text { down for COVID (EXPERT } \\
\text { candidate)* }\end{array}$ \\
\hline B & 57 & New cancer & $\begin{array}{l}\text { pT2N0M0 } \\
\text { Inv NST G3 Triple } \\
\text { negative; WLE and } \\
\text { SNB with adjuvant } \\
\text { radiotherapy and } \\
\text { chemotherapy }\end{array}$ & Surgery/NACT & $\begin{array}{l}\text { Would have considered NACT } \\
\text { but surgery was recommended } \\
\text { to avoid multiple trips to } \\
\text { hospital with } \\
\text { immunosuppression. } \\
\text { Would have elected immediate } \\
\text { contralateral reduction but was } \\
\text { delayed due to COVID policy } \\
\text { to avoid non-urgent surgery } \\
\text { with potential complications. }\end{array}$ \\
\hline C & 58 & New cancer & DCIS & Surgery & $\begin{array}{l}\text { DCIS surgery deferred due to } \\
\text { COVID. Followed up after } 3 \\
\text { months -WLE performed at } \\
\text { that time- restrictions lifted. }\end{array}$ \\
\hline $\mathrm{D}$ & 71 & New cancer & $\begin{array}{l}\text { PT1cN0M0 } \\
\text { Inv mucinous G1 } \\
\text { ER+PR+HER2- }\end{array}$ & Radiotherapy & $\begin{array}{l}\text { Radiotherapy not initiated } \\
\text { immediately post op - delayed } \\
3 \text { months. Commenced on } \\
\text { endocrine therapy in interim. } \\
\text { Operation in March. } \\
\text { Radiotherapy completed in } \\
\text { August. }\end{array}$ \\
\hline E & 67 & New cancer & DCIS & Surgery & $\begin{array}{l}\text { DCIS surgery cancelled, but } \\
\text { only delayed by } 10 \text { days- } \\
\text { restrictions lifted. }\end{array}$ \\
\hline $\mathrm{F}$ & 47 & New cancer & DCIS & Surgery & $\begin{array}{l}\text { No reconstruction offered post } \\
\text { mastectomy (low grade DCIS). } \\
\text { Referred to plastic surgery } \\
\text { team for delayed } \\
\text { reconstruction. }\end{array}$ \\
\hline G & 54 & New cancer & $\begin{array}{l}\text { pTicN0M0 Inv NST } \\
\text { G2 } \\
\text { ER+PR+HER2neg }\end{array}$ & Trial & $\begin{array}{l}\text { Not recruited for clinical trial } \\
\text { due to trial recruitment shut } \\
\text { down for COVID (EXPERT } \\
\text { candidate) * }\end{array}$ \\
\hline $\mathrm{H}$ & 61 & $\begin{array}{l}\text { Post op } \\
\text { cancer }\end{array}$ & $\begin{array}{l}\text { pT2N0M0 } \\
\text { Inv NST G3 } \\
\text { ER-PR-HER2pos }\end{array}$ & Surgery & $\begin{array}{l}\text { Not offered free flap despite } \\
\text { patient preference. Had } \\
\text { implant-based reconstruction. }\end{array}$ \\
\hline I & 52 & $\begin{array}{l}\text { Post op } \\
\text { cancer }\end{array}$ & $\begin{array}{l}\text { DCIS 12mm } \\
\text { intermediate grade }\end{array}$ & Radiotherapy & Boost to tumour bed omitted. \\
\hline
\end{tabular}




\begin{tabular}{|c|c|c|c|c|c|}
\hline Case & Age & Category & $\begin{array}{c}\text { Cancer } \\
\text { information }\end{array}$ & $\begin{array}{l}\text { Treatment } \\
\text { Changed }\end{array}$ & Details \\
\hline $\mathrm{J}$ & 59 & $\begin{array}{l}\text { Post op } \\
\text { cancer }\end{array}$ & $\begin{array}{l}\text { DCIS } 16 \mathrm{~mm} \\
\text { intermediate grade }\end{array}$ & Radiotherapy & Boost to tumour bed omitted. \\
\hline $\mathrm{K}$ & 61 & $\begin{array}{l}\text { Post op } \\
\text { cancer }\end{array}$ & $\begin{array}{l}\text { pTicN0M0 } \\
\text { Inv mucinous G2 } \\
\text { ER+PR+HER2equiv }\end{array}$ & Radiotherapy & $\begin{array}{l}\text { Radiotherapy delayed until } 4 \\
\text { months post operatively. } \\
\text { Commenced on Endocrine } \\
\text { therapy in interim. }\end{array}$ \\
\hline $\mathrm{L}$ & 35 & Post NACT & $\begin{array}{l}\text { pT1bN0M0 } \\
\text { Inv NST G3 Triple } \\
\text { positive }\end{array}$ & Surgery & $\begin{array}{l}\text { Requested bilateral mastecomy } \\
\text { but only offered unilateral. }\end{array}$ \\
\hline M & 56 & Post NACT & $\begin{array}{l}\text { IDC triple negative, } \\
\text { node positive, RCB- } \\
\text { II }\end{array}$ & Radiotherapy & $\begin{array}{l}\text { Treated with hypofractionated } \\
\text { radiotherapy rather than } \\
\text { conventional fractionated post- } \\
\text { mastectomy radiotherapy }\end{array}$ \\
\hline
\end{tabular}

\footnotetext{
*The EXPERT Trial is a randomized phase III trial of adjuvant radiation therapy versus observation following breast conserving surgery and endocrine therapy in patients with molecularly characterized luminal A early breast cancer. ${ }^{14}$

NACT=neoadjuvant chemotherapy
}

\section{Changes to chemotherapy}

Of 145 patients, 104 (71.7\%) involved a medical oncologist in their breast cancer management. Of the 104 patients, 30 (28.8\%) completed neoadjuvant systemic treatment and proceeded to surgery, 19 (18.3\%) commenced neoadjuvant or adjuvant chemotherapy +/- anti-HER2 treatment, 17 (16.3\%) proceeded to adjuvant endocrine therapy, 5 (4.8\%) did not receive any systemic treatment and 33 (31.7\%) had their medical oncology consultations after the study period.

One patient (B) experienced COVID-19 related changes to chemotherapy:

- Neoadjuvant chemotherapy was ideally recommended due to her grade 3 triple negative cancer with high proliferative index of $70 \%$. Ultimately up-front surgery was recommended to avoid multiple hospital visits and immunosuppression. She promptly underwent wide local excision and sentinel node biopsy (11 days after MDT discussion), followed by adjuvant chemotherapy (47 days after surgery) and radiotherapy.

There were no pandemic related changes to adjuvant chemotherapy regimens or dosing. However, prophylactic addition of pegfilgrastim to doxorubicin/cyclophosphamide (AC) chemotherapy was implemented in March 2020. None of the 16 patients who started AC experienced febrile neutropenia during the study period, compared to an average of two patients per month prior to this period.

The time intervals between MDT discussion and Medical Oncology consultation (nine days for neoadjuvant chemotherapy and 12 days for adjuvant chemotherapy) and subsequent first cycle of chemotherapy (12 days) were comparable to outside this time period without delay.

Patients on clinical trials continued treatment as per protocol without interruption, but telehealth safety monitoring was instigated during the study period. There was no new recruitment to clinical trials during this period.

\section{Changes to radiotherapy}

There were 124 of 145 women (85.5\%) recommended to receive radiotherapy. Of these, 99 (79.8\%) were consented for radiotherapy during the study period, 19 (15.3\%) were awaiting consent at the end of the study period, two (1.6\%) declined radiotherapy, one $(0.8 \%)$ was deemed unsuitable due to prior radiotherapy, and three $(2.4 \%)$ had their treatment at a different centre. COVID-related radiotherapy consent alterations only occurred in the first two months of the first wave of the pandemic. During this period, ultra-hypofractionation regimens such as the FAST Forward trial were not implemented in this centre. ${ }^{15}$ 
Five patients experienced a change to radiotherapy due to COVID-19.

- Two patients (D, K) had a delay to treatment start. Both were over 60 years of age with either a grade 1 or 2 tumour and were commenced on adjuvant endocrine therapy starting radiotherapy three months later.

- Three patients had changes to their radiotherapy protocols:

- Initially, a change in prescription to shorten the course of radiotherapy was recommended in five patients. However, between consent and initiation of treatment (2-5 weeks), two prescriptions were reverted to standard treatment. This involved one patient where a boost was to be omitted but was delivered, and one patient who was consented for a hypofractionated protocol but changed to conventional fractionation for whole breast and comprehensive nodal irradiation during the radiotherapy planning process as COVID-19 cases in NSW declined.

- Two patients had a boost to the surgical cavity omitted to shorten treatment course duration

- One patient received hypofractionated chest wall radiotherapy rather than conventional fractionated post-mastectomy radiotherapy post-NACT.

\section{DISCUSSION}

These results show that in the context of low pandemic burden, a minority of early breast cancer patients $(9.0 \%)$ received altered management, with the majority still receiving ideal treatment regimens. These findings provide reassurance that minimal patients may experience future recurrence as a result of 'less than ideal' management during the pandemic. The modest changes recorded are likely influenced by factors including reduced new presentations, institutional mitigative strategies and comparatively low COVID-19 transmission. These observations can provide insights in minimising compromises to oncological care for other institutions with improving COVID-19 rates and for future pandemics.

The changes to surgery, radiotherapy, and chemotherapy treatments were unlikely to impact significantly on risk of recurrence. The patient who was treated with up-front surgery rather than neoadjuvant chemotherapy is unlikely to have adverse effects from the change in sequencing. For other chemotherapy patients, the use of prophylactic G-CSF reduced the incidence of febrile neutropenia in neoadjuvant or adjuvant treatments and resulted in hospitalisations reducing substantially. Approximately $20 \%$ of patients may experience adverse events with bone pain, which can often be controlled with analgesia. Primary prophylaxis using pegylated G-CSF with AC may become routine treatment for the post-COVID-19 era.

Radiotherapy changes include two DCIS cases treated with whole-breast radiation with omission of a boost to the tumour bed. The benefit of a boost to the tumour bed for patients with non-low risk DCIS was not known until the publication of the TROG DCIS trial results in December 2020. ${ }^{16}$ One case of low-grade mucinous cancer experienced an intentional three-month delay to her radiotherapy treatment and commenced endocrine therapy in the interim. The likelihood of this significantly increasing risk of recurrence is considered very small.

Two patients were not referred for an eligible trial study during MDT discussions. Recommendation for trial therapy was not primarily discussed during these meetings and possibly many more patients referred for eligible trials at other points of management were not captured by this study. This has impacted the recruitment and progression of clinical trials suspended during this period.

Institutions abroad facing higher COVID-19 prevalence implemented stricter precautions to minimize the risk of infecting vulnerable cancer patients and experienced higher levels of resource competition. ${ }^{17-19}$ Strategies to cope included "hub and spoke” models, where a central facility coordinates care that is carried out in designated "COVID-19 free" satellite locations. ${ }^{17-19}$ Similarly in this study, most new referrals recommended for upfront surgery underwent their operations at COVID-free facilities within the same public hospital district or at locally affiliated private hospitals. This allowed the institution to focus on COVID management, protect surgical cancer patients from viral exposure, and utilize available resources in the private sector, which experienced a massive reduction in work-load during the suspension of elective surgeries. Breast cancer specific services and personnel remained largely operational during the study period, and were not significantly impacted by resource limitations. This was facilitated by a comparatively low burden of local COVID-19 cases in NSW. No patients in the study cohort were found to be COVID-19 positive although there may have been a low infection risk from isolated events of community transmission to healthcare staff who tested positive during this period.

Telemedicine is also being increasingly utilized for breast cancer management and follow-up appointments. Long terms consequences may still emerge such as potentially missing recurrences and early signs of complications due to the omission of clinical examination. Alternatively, it may encourage saving of healthcare resources and increase patient convenience. $^{20}$ 
The full impact of COVID-19 on early breast cancer may take years to understand as delayed presentations manifest. This study was conducted over the three-month period of most severe lockdowns and restrictions in NSW and showed a $25 \%$ reduction in new cancer referrals during the study period. This correlates to when the national screening program was closing down. ${ }^{2}$ Furthermore, national data demonstrated a decrease of $30-50 \%$ in Medicare benefits (Australian universal healthcare scheme) claimed for breast cancer diagnostic and treatment services in April/May 2020, with some recovery in later months. ${ }^{13}$ Significant reductions in new breast cancer referrals observed during lockdown period in Australia are reflected in other countries such as the UK where urgent new cancer referrals dropped by up to $80 \%$ in early 2020 , attributed to disrupted screening programs, reduced primary care presentations, and more cautious health-seeking behaviours. ${ }^{21,} 22$ Diagnostic delays may be associated with a backlog of patients who could present with more advanced disease requiring more complex treatment courses involving systemic therapies, upgraded surgical procedures, and poorer outcomes. ${ }^{21,} 23$ The national BreastScreen program has already observed a surge of 12000 screening mammograms in July to September 2020 following re-opening, compared to the same period in 2018. ${ }^{24}$ Modelling of the impact of diagnostic delays for patients presenting in a 12 month period under different COVID-19 scenarios estimates an increased number of deaths due to breast cancer by $7.9-9.6 \%$ in the ensuing 5 year period. ${ }^{22}$

These flow-on effects affect not only new patients at diagnosis and primary management but cause delays to "non-urgent" treatments, such as reconstructive procedures. After non-urgent surgeries were suspended between March and July 2020 in the NHS, there is now a backlog of over 1500 patients awaiting post mastectomy breast reconstructions. ${ }^{25}$

This study has some strengths and limitations. The strengths include the prospective documentation of 'ideal' treatment plans and COVID-related changes through robust data collection by the MDT. This was limited by excluding post-operative patients who were already receiving adjuvant treatment during the study period as they had treatment plans decided preCOVID. This study also did not measure the psychological impact of treatment changes, which may be significant. Several patients were unable to have their preferred plans for breast reconstruction even though the importance of choice for these treatments on psychological well-being has been documented. ${ }^{26}$ Further research is needed to explore the impacts on quality of life by changes to treatment related to COVID-19, and the psychological impacts of a cancer diagnosis at this time of heightened overall distress in the community. A further limitation is that patient-reported outcomes were not collected. The study did not continue beyond mid-2020 to see if there was a 'catch-up' in referrals, as would be expected according to national data. ${ }^{13}$ Also, follow-up data is not available at this stage, and this will be required to evaluate the impact of changes to treatment.

Much of the research on COVID-19 impacts on breast cancer care comprises observational, single centre data, to which this paper contributes perspectives from a low pandemic burden institution. For healthcare systems integrating pandemic-related strategies into mid and long-term practice, larger multicentre studies and systematic reviews are required to establish evidence-based protocols. As vaccination programs roll out, countries entering recovery status may take precedent from countries with low pandemic burden when accounting for surging capacity in routine screening and treatment. Similarly, countries with rising cases related to easing lockdowns and spread of new COVID strains may more quickly adopt proven guidelines to protect cancer patients from infection while preserving ideal oncological outcomes. Approximately 12 months from the lifting of the initial lock-down, Sydney experienced a second wave of COVID-19 caused by the Delta variant, so the experience obtained from the first wave was put into practice again.

\section{CONCLUSION}

Despite the temporary cessation of breast cancer screening, restrictions on surgery and modified radiotherapy and chemotherapy recommendations, $91.0 \%$ of patients at our institution received standard care for their breast cancer during the first wave of the COVID-19 pandemic in NSW. This was possible due to the relatively small COVID-19 incidence in Australia, combined with partnerships between public and private hospitals to facilitate the provision of urgent cancer surgery. Review of the cases experiencing a change to treatment shows that the modifications are unlikely to be of oncological significance. It is possible, however, that the restricted access to breast reconstruction and contralateral surgery options may have quality of life implications which will be addressed in the follow-up of these

\section{CONFLICT OF INTEREST}

RH has participated in advisory boards for AstraZeneca, Bristol Myers Squibb, Eli Lilly, Merck, Merck Sharp and Dohme, Novartis, Oncosec, Pfizer, Roche and Seagen and has received speaker honoraria from Merck Sharp and Dohme, Novartis and Roche. EE has participated in advisory board for Merck Sharp and Dohme. 
There are no conflicts of interests to declare for the other authors. There were no funding sources to declare. All authors confirm that they had full access to all the data in the study.

\section{REFERENCES}

1. NSW Government (Health). COVID-19 Resumption of elective surgery: NSW Health; 2020 [Available from: https://www.health.nsw.gov.au/Infectious/covid19/Pages/resumption-of-elective-surgery.aspx.

2. Government DoHoA. What is happening with Breast Screen services? 2020 [Available from: http://www.cancerscreening.gov.au/internet/screenin g/publishing.nsf/Content/frequently-asked-questions.

3. Breast Surgeons of Australia and New Zealand. Position statement regarding breast reconstruction during the COVID-19 pandemic 2020 [Available from: https://www.breastsurganz.org/news/breastreconstruction-during-the-covid-19-pandemic/.

4. Breast Surgeons of Australia and New Zealand. Guidelines from BreastSurgANZ Council relating to the COVID-19 pandemic 2020 [Available from:

5. https://www.breastsurganz.org/news/guidelinesrelating-to-the-covid-19-pandemic/.

6. Peter MacCallum Cancer Centre. COVID-19 - DRO Clinical Response Plan March 2020. Vic2020.

7. Filippi AR, Russi E, Magrini SM, Corvo R. Letter from Italy: First practical indications for radiation therapy departments during COVID-19 outbreak. Int J Radiat Oncol Biol Phys. 2020;107(3):597-9.

8. Royal Australasian and New Zealand College of Radiologists. Principles for radiation oncology practices. Royal Australasian and New Zealand College of Radiologists,. 2020.

9. Dietz JR, Moran MS, Isakoff SJ, Kurtzman SH, Willey SC, et al. Recommendations for prioritization, treatment, and triage of breast cancer patients during the COVID-19 pandemic. the COVID-19 pandemic breast cancer consortium. Breast Cancer Res Treat. 2020;181(3):487-97.

10. Segelov E, Underhill C, Prenen H, Karapetis C, Jackson C, et al. Practical Considerations for Treating Patients With Cancer in the COVID-19 Pandemic. JCO Oncol Pract. 2020;16(8):467-82.

11. European Society for Medical Oncology. ESMO Management and Treatment Adapted Recommendations in the COVID-19 Era: Breast Cancer: European Society for Medical Oncology; 2020 [Available from: https://www.esmo.org/guidelines/breastcancer/breast -cancer-in-the-covid-19-era.]

12. Department of Health of Australian Government. Coronavirus (COVID-19) current situation and case numbers Australian Government; 2021 [Available from: https://www.health.gov.au/news/healthalerts/novelcoronavirus-2019-ncov-healthalert/coronaviruscovid-19-currentsituation-and-case-numbers\#.]

13. NSW Goverment. Find the facts about COVID-19: NSW Government: NSW Government, 2020 [Available from: https://www.nsw.gov.au/covid19/find-facts-about-covid-19.]

14. Cancer Australia. Review of the impact of COVID-19 on medical services and procedures in Australia utilising MBS data: Skin, breast and colorectal cancers, and telehealth services. Surry Hills, NSW: Cancer Australia; 2020.

15. Breast Cancer Trials. EXPERT ANZ 1601: EXPERT: ANZ Breast Cancer Trials Group Ltd; 2021 [Available from: https://www.breastcancertrials.org.au/currentclinical-trials/expert.

Murray Brunt A, Haviland JS, Wheatley DA, Sydenham MA, Alhasso A, et al. Hypofractionated breast radiotherapy for 1 week versus 3 weeks (FAST-Forward): 5-year efficacy and late normal tissue effects results from a multicentre, noninferiority, randomised, phase 3 trial. Lancet. 2020;395(10237):1613-26.

16. Chua BH, Link E, Kunkler I, Olivotto I, Westenberg $\mathrm{AH}$, et al., editors. A randomized phase III study of radiation doses and fractionation schedules in nonlow risk ductal carcinoma in situ (DCIS) of the breast (BIG 3-07/TROG 07.01). San Antonio Breast Cancer Symposium; 2020.

17. Viale G, Licata L, Sica L, Zambelli S, Zucchinelli P, et al. Personalized Risk-Benefit Ratio Adaptation of Breast Cancer Care at the Epicenter of COVID-19 Outbreak. Oncologist. 2020;25(7):e1013-e20.

18. Highton LR, Dave RV, Barnes NLP. Breast cancer surgery during the COVID-19 pandemic. Br J Surg. 2020;107(10):e380.

19. Acea-Nebril B, Garcia-Novoa A, Garcia-Jimenez L, Escribano-Posada C, Diaz-Carballada C, et al. Impact of the COVID-19 pandemic on a breast cancer surgery program. Observational case-control study in a COVID-free hospital. Breast J. 2020;26(12):242830.

20. Al-Shamsi HO, Alhazzani W, Alhuraiji A, Coomes EA, Chemaly RF, et al. A Practical Approach to the Management of Cancer Patients During the Novel Coronavirus Disease 2019 (COVID-19) Pandemic: An International Collaborative Group. Oncologist. 2020;25(6) :e936-e45. 
21. Cancer Australia. COVID-19 Recovery: Implications for cancer care Surry Hills, NSW: Cancer Australia; 2020.

22. Maringe C, Spicer J, Morris M, Purushotham A, Nolte $\mathrm{E}$, et al. The impact of the COVID-19 pandemic on cancer deaths due to delays in diagnosis in England, UK: a national, population-based, modelling study. Lancet Oncol 2020;21(8):1023-34.

23. Sud A, Jones ME, Broggio J, Loveday C, Torr B, et al. Collateral damage: the impact on outcomes from cancer surgery of the COVID-19 pandemic. Ann Oncol. 2020;31(8):1065-74.
24. Australian Institute of Health and Welfare. Cancer screening and COVID-19 in Australia. 2020.

25. Campbell D. More than 1,500 NHS breast reconstructions delayed due to Covid. The Guardian. 2020.

26. Flitcroft K, Spillane A, Brennan M, Snook K, Costa D, et al. The importance of choice: A prospective evaluation of factors affecting preference for immediate, delayed or no breast reconstruction in the context of mastectomy and post-mastectomy radiotherapy for breast cancer. Eur J Surg Oncol. 2015;41.

\section{How to Cite This Article}

Zhang E, Stuart K, Hui R, Mellor R, Wang R, Ahern V, et al. Management of Early Breast Cancer at an Australian Cancer Centre During the Early Phase of COVID-19 Pandemic. Arch Breast Cancer. 2021; 16(4):318-328.

Available from: https://www.archbreastcancer.com/index.php/abc/article/view/443 